\title{
Infant's Negative Emotionality as a Potential Moderator Between Teacher's Emotion-Related Socialization Behaviors and Infant's Emotional Intelligence
}

\author{
So Ra Bae ${ }^{1}$, Sunhee Kim² \\ 교사의 정서사회화 행동과 영아의 정서지능 간의 관계: \\ 부정적 정서성의 조절효과 \\ 배소라 ${ }^{1}$, 김선희 ${ }^{2}$ \\ 부산대학교 아동가족학과 박사과정생, 부산대학교 아동가족학과 교수 ${ }^{2}$
}

Doctoral Student, Department of Child Development and Family Studies, Pusan National University, Busan, Korea Professor, Department of Child Development and Family Studies, Pusan National University, Busan, Korea ${ }^{2}$

\begin{abstract}
Objectives: This study aimed to identify the role of teachers' emotion-related socialization behaviors in the development of an infant's emotional intelligence and the moderating role of their negative emotionality on it.

Methods: Data were collected from 198 two-year-old infants (boys $=88$, girls $=110$ ) and their child care teachers. Descriptive statistics were computed, and Pearson's correlation and PROCESS macro (model 1) was used for data analysis.

Results: The study found that the relationship between teachers' emotion-related socialization behaviors and infants' emotional intelligence could be deteriorated by the infants' emotionality. More specifically, their low levels of emotionality showed a significant moderating effect on the relationship between the teachers' minimization or punitive reactions and the infants' emotional intelligence.

Conclusion: These results indicate that infants' negative emotionality and the teachers' response to it could hamper the development of infants' emotional intelligence, and provide a basis for relevant education and programs for preventive interventions.
\end{abstract}

Keywords: infant's emotional intelligence, negative emotionality, teacher's emotion-related socialization behaviors, differential susceptibility model

\section{Introduction}

보육기관을 이용하는 영아가 증가함에 따라 양육환경이 가정 에서 보육기관으로 확대되고 있다. 이로 인해 영아들은 어머 니와 장시간 분리되는 경험과 함께 보육기관에서 새로운 환경 의 규칙을 따르며 타인과의 관계 형성, 단체생활 적응 등 다양

Corresponding Author: Sunhee Kim, Professor, Department of Child Development and Family Studies, Pusan National University, 2, Busandaehak-ro 63beon-gil, Geumjeong-gu, Busan, Korea

E-mail: kremedy@pusan.ac.kr
한 요구에 직면하게 된다. 이는 경험이 제한적이고 대처능력 이 부족한 영아들에게 어려운 도전이자 스트레스로 작용할 수 있으므로, 자신이 속한 환경에서 성공적으로 적응하고 대처 할 수 있는 능력인 정서지능(emotional intelligence)이 요구된다 (Goleman, 1995, 2001).

정서지능이란 자신의 정서를 정확하게 인식하고 상황에 따

(C)The Korean Association of Child Studies

This is an Open Access article distributed under the terms of the Creative Commons Attribution Non-Commercial License (http:// creativecommons.org/licenses/by-nc/4.0) which permits unrestricted noncommercial use, distribution, and reproduction in any medium, provided the original work is properly cited. 
라 충동을 억제하여 정서를 적절하게 조절하며 타인의 사고, 감정, 의도를 파악하는 등 적응적인 방식으로 정서를 활용하 는 능력을 의미한다(Salovey \& Mayer, 1990). 정서지능의 기초 는 0세부터 3세 사이의 영아기에 형성된다(Moon, 2011). 특 히, 만 2 세는 영아기에서 유아기로 이행되는 시기로 타인의 정 서를 인식하고 정서를 표현하는 능력이 향상되며, 자신의 정 서를 상황에 맞게 조절하려고 시도하는 등 정서지능이 발달한 다(Kang \& Kim, 2018). 이러한 영아기의 정서지능은 타인과 안정적이고 지속적인 관계를 맺을 수 있는 기본 도구로서 역 할을 하며(Moon, 2011), 이후 발달과정에서도 사회적 적응과 밀접한 관련이 있다.

정서지능은 또래유능성(B. Y. Kim, 2016), 리더십(E. K. Kim \& Kim, 2019), 문제행동(N. H. Kim, Yeon, \& Oh, 2018), 학교 생활 적응에 긍정적인 영향을 미친다(Denham et al., 2012). 뿐 만 아니라 이후 학업수행 및 성취에 중요한 역할을 하는 것으 로 나타나(Salovey \& Mayer, 1990), 불안함을 느낄 때 정서를 조 절하여 동기부여에 활용함으로써 높은 학업수행력을 보인다 (O.-B. Jung, Chung, \& Lim, 2007). 이처럼 정서지능은 사회적. 정서적.개인적 능력의 집합체로 성장과정에서 직면하는 사회 적 요구와 환경적 스트레스에 대처할 수 있게 하는 등 성공적 인 적응을 예측하는 요인이다(Bar-On, 2000). 따라서 정서지 능의 기초를 마련하는 결정적 시기인 만 2세 영아기에 초점을 맞춰 정서지능을 향상시킬 수 있는 관련 변인들을 탐색할 필 요가 있다.

이와 관련하여 선행연구들은 영유아의 초기 경험의 중요성 을 근거로 가장 밀접한 사회적 관계를 형성하는 대상인 부모 에 관심을 가져왔다. 부모의 언어통제유형(B. W. Cho, 2012), 심리적 안녕감(Y. H. Yoon \& Shim, 2017) 등이 정서지능 발달 에 유의미한 영향을 미칠 수 있음이 보고된 바 있으며, 부모 의 양육행동에 초점을 둔 연구들이 주를 이룬다(M.-S. Choi, Kong, \& Park, 2012; Kang \& Kim, 2018; J. Y. Lee, Lee, Jang, \& Sung, 2019). 하지만 정서지능은 개인이 접하는 환경의 정서 적 경험을 통해 발달될 수 있다는 점을 근거로(Paterson et al., 2012) 일반적인 양육행동과 구분되는 정서사회화 행동에 주 목할 필요성이 제기되고 있다(Alegre, 2011). 정서사회화 행동 이란 자녀의 정서를 사회화하는 과정에 개입하는 정서적 양육 행동을 의미하며, 사회.문화적으로 적합한 방식으로 정서를 표현하고 관리할 수 있도록 이에 대한 학습의 기회를 제공한 다(Eisenberg, Cumberland, \& Spinrad, 1998). 정서사회화 행동 의 하위요인들은 부정적 정서에 대한 반응, 정서표현성, 정서 지도 등이 포함되고 있으나(Eisenberg et al., 1998), 연구자들에
따라 다소 다르게 제안되고 있다. 선행연구들은 양육자가 자 녀의 정서적 표현에 대해 반응할 때 정서지도도 함께 이루어 진다는 점에서 영유아기 자녀에 대한 정서사회화 행동으로 부 정적 정서에 대한 반응과 정서표현성에 초점을 두고 있다(E. Cho \& Shin, 2015). 따라서 본 연구에서도 이를 중점적으로 다 루고자 한다.

먼저, 자녀의 부정적 정서에 대한 반응은 지지적인 반응과 비지지적인 반응으로 구분되며, 자녀의 부정적 정서에 대해 지지적인 반응을 보일 시 부정적 정서가 쉽게 해소됨에 따라 부모와 자녀가 부정적 정서 경험에 대해 대화를 나눌 수 있게 되고, 이러한 과정에서 정서지능이 발달될 수 있다(E. Cho \& Shin, 2015). 이와 반대로 비지지적인 반응을 보이게 되는 경 우, 자녀가 정서조절이 필요한 상황에서 혼란스러움을 느낄 수 있으며(Albrecht, Burleson, \& Goldsmith, 1994), 정서지능 발 달을 저해할 수 있다(K. M. Jung, Yoon, \& Ahn, 2017). 다음으 로 부모의 정서표현성은 긍정적 정서표현성과 부정적 정서표 현성으로 구성되며, 특히 긍정적 정서표현은 아동이 학습과 문제해결에 적극적으로 참여하게 만들어 정서지식(Denham, 1998)과 정서지능을 발달시키는 것으로 보고된다(Nam \& Seo, 2008). 이러한 결과는 양육자의 정서사회화 행동이 영아 의 정서지능 발달에 영향을 줄 가능성을 암시한다. 이처럼 선 행연구들에서 양육자의 정서사회화 행동에 대한 중요성이 지 속적으로 증명되어왔으나 그 대상은 부모에 국한되어 있다 (Denham, Bassett, \& Zinsser, 2012).

최근 영아들이 보육기관에서 교사와 함께 하는 시간이 증 가함에 따라 교사가 이차적 양육자로 영향력이 커지고 있는 현 시점을 감안할 때, 영아의 정서지능에 미치는 교사의 영향 을 살펴볼 필요가 있다. 영아는 교실의 하루 일과에서 다양한 정서를 경험하게 된다. 가령, 교실에서는 사회적 상호작용에 서 원하는 활동을 지연하고 집중을 해야 하거나 새롭고 어려 운 과제에 참여하면서 좌절감을 느끼기도 한다(Rim-Kaufman, Pianta, \& Cox, 2000). 이때 교사가 정서에 대해 격려해주면 좌 절감을 느끼는 상황을 다루는 방법을 배울 수 있어 사회정서 능력 발달에 도움을 줄 수 있다(Bassett et al., 2017). 간혹 영유 아는 상황에 따라 정서적 해석이 정확하지 않을 수 있는데, 이 때 교사가 행동단서나 상황단서에 주의를 기울일 수 있도록 도와줄 시 상황에 따라 정서가 달라질 수 있음을 알게 되는 등 정서이해능력이 증진될 수 있다(Kostelnik, Soderman, Whiren, Rupiper, \& Gregory, 2015). 또한, 교사와 영아가 직접적으로 상호작용하지 않더라도 교사와 또래 간의 상호작용을 관찰 함으로써 교실의 정서적 규범을 배우며 정서적 능력을 향상 
시킬 수 있다(Denham, \& Bassett, 2019). 이처럼 교실의 전체적 인 맥락에서 교사가 나타내는 정서사회화 행동은 영아가 정서 와 상황에 맞는 적절한 행동에 대해 배울 수 있으며(Valiente, Swanson, DeLay, Fraser, \& Parker, 2020), 이러한 맥락적 차이는 가정환경과는 다른 독특성을 가질 수 있다(Denham, \& Bassett, 2019; Denham, Ferrier, \& Bassett, 2020). 하지만, 교사의 정서사 회화 행동이 영아의 정서지능에 미치는 영향력을 검증한 연구 는 제한적인 실정이므로 이에 대해 살펴볼 필요성을 제기한다.

한편, 정서지능 영향을 미치는 개인적 요인은 놀이성(Park, $\mathrm{Kim}, \& \mathrm{Bae}$ ), 자율성(S.-J. Yoon \& Park, 2016) 등에 관한 연구 들이 제시된 바 있으며, 기질에 초점을 맞춘 연구들이 주를 이 룬다. 이때, 초기 기질의 중요한 요소로 기질의 정서적 반응 측 면인 부정적 정서성이 제시되고 있다(Rothbart \& Bates, 2006). 부정적 정서성은 자극에 대한 짜증, 높은 수준의 부정적 반응 이나 새로운 것에 대한 불안을 포함한다. 영아는 자신을 방어 하고, 욕구충족, 목표 달성을 위해 부정적 정서를 나타내는데 (Izard, 1991), 이는 위험하거나 갈등이 있는 상황을 인식하게 하는 등 환경에 대한 적응적 대처의 중심과정이라 볼 수 있다 (Y. E. Kim, 2014). 2세경에는 자율성이 발달함에 따라 자기주 장이 강하게 나타나 부정적 정서를 자주 표출하게 된다(J. Oh, 2010). 이때, 부정적 정서성의 양과 빈도에는 개인적인 차이가 있다(E. S. Choi, 2002). 부정적 정서성이 높은 영아는 자기정 서를 이해하는 것에 어려움을 보인다(J. Y. Kim, Dah, \& Kim, 2008). 또한, 상황을 보다 부정적으로 해석하는 경향이 있으며 이러한 사고과정이 습관화되면서 정서조절(J. E. Kim \& Shin, 2015)과 정서지능에 어려움을 보이게 된다(I.-Y. Cho, 2016). 이로 인해 이후 발달에서도 또래 상호작용에서 어려움을 보 이거나(Yoo \& Yi, 2016), 외현화 문제행동이 나타날 수 있다(J. Choi \& Shin, 2018).

이처럼 부정적 정서성은 이후 발달과정에서 취약요인으로 작용할 수 있다는 점에서 부정적인 요인으로 인식되어 왔으나 차별적 민감성 모델(differential susceptibility model)에 따르면 부정적 정서성이 주변 자극에 대한 민감성의 요인으로 작용하 여, 긍정적인 반응을 경험할 시 다른 영아에 비해 민감하게 반 응함에 따라 그 효과가 크게 나타나 높은 성취와 적응력을 발 달시킬 수 있는 반면, 부정적인 반응을 경험하면 부적응적인 발달적 결과를 초래할 수 있다고 주장한다(Belsky, 2013; Belsky \& Pluess, 2009). 즉, 부정적 정서성이 반드시 부정적인 결과를 야기한다고 볼 수 없으며, 영아의 주변 환경 자극에 따라 달라 질 수 있음을 가정할 수 있다. 차별적 민감성 모델에 기초한 선 행연구에 의하면 부정적 정서성이 높은 유아가 낮은 수준의
보육환경에 직면했을 때, 더 많은 문제행동을 보였으나 양질 의 보육 경험을 하게 될 시 문제행동 수준이 낮은 것으로 나타 났다(Belsky \& Pluess, 2009). 이처럼 차별적 민감성 모델을 뒷 받침하는 결과들이 보고되고 있으나 문제행동 수준의 감소 여 부를 긍정적인 발달적 결과로 보는 것에는 제한이 있다(Belsky \& Pluess, 2009). 이를 근거로 차별적 민감성 가설을 검증함에 있어 긍정적인 발달적 결과로서 영아의 정서지능을 살펴봐야 할 필요성이 제기된다. 동시에 교사의 정서사회화 행동이 영 아의 정서지능에 미치는 영향은 영아의 부정적 정서성 수준에 따라 달라질 수 있음을 예측해 볼 수 있다.

종합하면, 교사가 애정적이며 지지적인 정서사회화 행동을 제공함으로써 영아는 부정적 정서에 대한 추론과 정서표현 등 을 발달시킬 수 있으며 결과적으로는 정서지능이 향상될 수 있다. 더불어 차별적 민감성 모델에 근거해 영아의 부정적 정 서성이 민감성이라는 긍정적인 요인으로 작용하여 부정적 정 서성 수준에 따른 교사의 정서사회화 행동이 영아의 정서지 능에 영향을 끼치는 주요 요인으로 기능함을 예측할 수 있다 는 점에서 이를 검증해 볼 필요성을 제기한다. 이에 본 연구에 서는 차별적 민감성 모델을 기초로 교사의 정서사회화 행동과 영아의 정서지능 간의 관계에서 영아의 부정적 정서성의 조절 효과를 밝히고자 한다. 이를 통해 만 2 세 영아의 정서지능에 미치는 요인을 확인하고, 부정적 정서성 수준에 따른 교사의 개입이 영아의 정서지능에 영향을 미칠 수 있다는 점을 검증 함으로써 교사의 중재 방법에 대한 구체적인 정보를 파악하여 보육현장에 실제적인 기여하고자 한다. 이러한 본 연구의 필 요성에 근거하여 설정한 연구문제는 다음과 같다.

\section{연구문제 1}

영아의 부정적 정서성은 교사의 정서사회화 행동과 영아의 정서지능 간의 관계를 조절하는가?

\section{Methods}

\section{연구대상}

본 연구의 대상은 부산, 울산, 경남에 소재한 55 곳의 어린이 집에 재원하고 있는 만 2 세 영아 198 명과 담당 보육교사 142 명이다. 연구대상 영아의 교사들이 근무하고 있는 기관유형 은 민간 어린이집이 90 곳(63.4\%)으로 가장 많았고, 국공립 어 린이집 31 곳 $(21.8 \%)$, 직장 어린이집 13 곳 $(9.2 \%)$, 가정 어린이 
집 4곳(2.8\%)과 법인 어린이집 4곳(2.8\%) 순으로 나타났다. 영아의 성별 비율은 남아 88 명(44.4\%), 여아 110 명(55.6\%)으 로 여아가 다소 많았다. 영아의 월령별 분포는 24 개월에서 26 개월이 10 명 $(5.1 \%), 27$ 개월에서 29개월이 23명(11.6\%), 30개 월에서 32 개월이 42 명(21.2\%), 33개월에서 35개월이 123 명 (62.1\%)으로 33 개월에서 35 개월에 해당하는 영아의 수가 가 장 많았으며, 대상 영아의 평균 월령은 32.5 개월 $(S D=2.84)$ 이었다. 보육교사의 성별은 모두 여성이며, 연령은 35 세 이 상이 78명(54.9\%)으로 가장 많았으며, 25세 이상 30세 미만 33 명(23.2\%), 30세 이상 35세 미만 24명(16.9\%), 24세 이하 7 명 $(4.9 \%)$ 순으로 나타났다. 교사의 경력은 1 년 미만이 4 명 (2.8\%), 1 년 이상 3 년 미만이 31명(21.8\%), 3년 이상 5년 미만 이 31명(21.8\%), 5년 이상 7년 미만이 22명(15.5\%), 7년 이상 10 년 미만이 23명(16.2\%), 10년 이상이 31명(21.8\%)이었다. 교사의 학력은 전문대 졸업이 70명(49.3\%)으로 가장 많았으 며, 대학교 졸업 47 명(33.1\%), 대학원 이상 11 명(7.7\%)과 보육 교사 교육원 졸업 14 명 $(9.9 \%)$ 순이었다.

\section{연구도구}

\section{영아의 정서지능}

영아의 정서지능을 측정하기 위해 Salovey와 Mayer (1990) 및 Goleman (1995)의 이론을 근거로 K. H. Kim (1998)이 개발한 유아 정서지능 척도를 H.-J. Kim (2005)이 영아용으로 수정 보 완한 영아 정서지능 척도를 사용하였다. 이 척도는 자기 정서 의 인식 및 표현(7문항)과 감정의 조절 및 충동억제(9문항), 자 기정서의 이용(11문항), 타인정서의 인식 및 배려(10문항), 교 사관계(5문항), 또래관계(3문항)로 구성되며, 하나의 변인으 로 합산하여 사용하였다. 문항의 예로는 "기쁜 일이 있는 경우 다른 사람에게 자기 감정을 표현한다.”, "영아가 자신의 격한 감정을 스스로 억제하려한다.", "다른 사람을 고려하여 자신 이 하고 싶은 일도 참는다.”, “새로운 친구하고도 쉽게 어울린 다.” 등이 있다. 각 문항은 서로 상반된 의미를 가진 한 쌍의 진 술문으로 제시되며, 5 단계 도식으로 평정하는 Likert식 척도로 영아의 담당 보육교사가 평가한다. 전체 문항 중 부정 문항(11 문항)은 역채점 후 사용하였으며, 가능한 총점의 범위는 45점 225점까지로 점수가 높을수록 영아의 정서지능이 높음을 의미한다. 본 연구에서 산출된 전체 문항에 대한 내적합치도 계수 Cronbach's $\alpha$ 는 .95로 나타났다.

\section{영아의 부정적 정서성}

영아의 기질은 Putnam, Gartstein과 Rothbart (2006)가 개발한 Early Childhood Behavior Questionnaire-Short Form (ECBQ-SF) 를 Yoo와 Yi (2016)가 수정.번안한 척도를 사용하였다. ECBQ$\mathrm{SF}$ 는 $\mathrm{ECBQ}$ 의 축약형으로 외향성, 의도적 통제, 부정적 정서 의 3 가지 요인으로 구성되어 있으나 본 연구에서는 부정적 정 서를 측정하는 12 문항을 사용하였다. 문항의 예로는 "화가 나 면 위로받아도 3 분 이상 운다.”, “아이가 무언가 해달라고 요 청했는데 “안돼'라는 말을 들으면 성질을 부린다.” 등이 있다. 각 문항은 5점 Likert식 척도로 영아의 담당 보육교사가 평가 한다. 전혀 그렇지 않다(1점)에서 매우 그렇다(5점)로 평정하 며, 해당 사항이 없는 행동에 대해서는 해당 사항 없음으로 표 시한다. 해당 사항 없음으로 표기된 문항은 그 문항이 포함된 하위영역의 총점 평균을 산출하여 점수를 부여한다. 전체 문 항 중 부정 문항(12번)의 경우 역채점하였으며, 가능한 총점의 범위는 12-60점까지로 점수가 높을수록 영아의 부정적 정서 성이 높음을 의미한다. 본 연구에서 산출된 내적합치도 계수 Cronbach's $\alpha$ 는 .84로 나타났다.

\section{영아의 부정적 정서성}

부정적 정서에 대한 교사 반응 영아의 부정적 정서에 대한 교 사 반응을 측정하기 위해 Fabes, Eisenberg와 Bernzweig (1990) 가 개발한 The Coping with Children's Negative Emotions Scale (CCNES)을 Denham, Bassett과 Miller (2017)가 교사용으로 수 정·보완한 척도를 사용하였다. 본 척도는 영아가 부정적 정서 를 느낄 수 있는 10 가지 상황에 대한 교사의 반응을 측정하기 위한 것이다. 척도는 제작자의 허락을 받아 본 연구자가 1 차로 번안하고 이중 언어를 사용하는 아동가족학 전공 대학원생 1 인이 2 차 번안을 한 후, 원척도와의 일치도를 검토하였으며 연 구자와 아동가족학 전공 박사과정 1 인과 아동학 전공 교수가 문항의 적절성을 재검토한 뒤 사용하였다.

측정도구의 타당성 검증을 위하여 확인적 요인분석을 실시 한 결과, 공통성 0.4 이하인 문항과 교차부하로 판단되는 문항 등 총 17 문항을 제외한 후 최종 분석을 실시하였다. 최종 분석 에 사용된 문항은 정서중심 반응 16문항(예: "영아를 위로해주 고, 영아가 즐거운 일을 떠올릴 수 있도록 도와준다.”), 최소화 반응 9문항(예: “영아에게 그 일은 울 일이 아니라고 말한다."), 처벌적 반응 7문항(예: “영아에게 계속 울면, 다른 재미있는 놀 이를 못하게 할 것이라고 말한다.”), 스트레스 반응 4문항(예: 
“영아의 부주의함에 대해 흥분하며 신경질을 낸다.”), 감정표 현중심 반응 3문항(예: "영아에게 속상하면 울어도 괜찮다고 말한다.”), 감정표현격려 반응 4문항(예: “영아가 자신의 불안 한 마음을 이야기할 수 있도록 격려한다.”)의 총 43문항이 6 개의 하위요인으로 구성된다. 각 문항은 7점 Likert식 척도로 영아의 담당 보육교사가 평가한다. 전체 문항 중 부정 문항-(7, 33,43 번)의 경우 역채점 하였으며, 점수가 높을수록 부정적 정서에 대한 교사 반응이 높음을 의미한다. 각 하위요인의 총 점의 범위는 43-301점까지로 점수가 높을수록 영아의 부정적 정서성이 높음을 의미한다. 본 연구에서 산출된 전체 문항에 대한 내적합치도 계수 Cronbach's $\alpha$ 는 .81이었다. 하위요인별 내적합치도 계수 Cronbach's $\alpha$ 는 .73 .92로 나타났다.

교사의 정서표현성 교사의 정서표현성을 측정하기 위 해 Halberstadt (1986)의 Family Emotional Expressiveness Questionnaire (FEQ)를 K. Y. Choi와 Woo (2001)가 수정·번안 하고, S. M. Oh (2017)가 수정.보완한 척도를 사용하였다. 본 척도는 보육기관에서 일어날 수 있는 다양한 상황에서 교사의 정서표현성을 측정하기 위한 것으로, 긍정적 정서표현성(17 문항)과 부정적 정서표현성( 8 문항)의 2 가지 요인으로 구성되 어 있으며, 총 25 문항이다. 문항의 예로는 "유아에 대한 애정 을 말과 행동으로 표현한다.”, “유아의 부주의함에 분노를 드 러낸다." 등이 있다. 각 문항은 5점 Likert식 척도로 영아의 담 당 보육교사가 평가한다. 교사의 긍정적 정서표현성 및 부정 적 정서표현성 점수가 높을수록 해당 정서를 많이 표현하는 것을 의미한다. 본 연구에서 산출된 전체 문항에 대한 내적합 치도 계수 Cronbach's $\alpha$ 는 .83이었다. 하위요인별 내적합치도 계수 Cronbach's $\alpha$ 는 긍정적 정서표현성 .92, 부정적 정서표현 성 .87으로 나타났다.

\section{연구절차}

\section{예비조사}

예비조사는 2019년 7월 20일부터 2019년 8월 20일까지 온라 인 조사를 통해 만 2세 영아를 담당하고 있는 교사 54 명을 대 상으로 실시되었다. 예비조사의 목적은 본 조사를 실시하기 전에 연구도구의 적절성을 파악하고 보완하는 것에 있다. 본 조사에 참여하지 않는 교사를 대상으로 교사의 정서사회화 행 동에 대한 예비조사를 실시하였다. 교사의 정서사회화 행동에 대한 문항을 검토하였으며, 교사의 최소화 반응 중 “영아에게
울 일이 아니라고 말한다.”의 경우, 교육적인 측면에서 언급할 수 있다는 점에서 중의적인 표현이라고 생각하였다. 따라서 문항 뒤에 예시를 추가하여 "영아에게 그 일은 울 일이 아니라 고 말한다(예: 아기들이나 우는 거야).”로 수정하였다. 또한, 기 관 이외의 프로그램 활동에 대해 '발표회’로 수정하여 번역하 였으나 만 2세의 경우 발표회 및 학예회가 없는 곳도 있어 보 편적으로 하는 행사를 예시로 들어 '발표회(예: 동요부르기 대 회)'라고 수정하였다. 이외의 별다른 문제는 발견되지 않았다.

\section{본조사}

본 조사는 2019년 8월 21일부터 2019년 9월 10일까지 연구자 가 임의로 선정한 부산, 울산, 경남에 소재한 55 개 어린이집에 서 실시되었다. 본 조사에 앞서 연구자가 각 어린이집의 원장 에게 연구목적, 예상 소요시간, 응답 시 주의사항에 대한 설명, 동의를 얻는 절차를 거쳤다. 배포된 281부의 설문지 중 226부 가 회수되었으며 이 중 문항이 누락되거나 불성실한 응답자료 28 부를 제외한 198 부가 최종 분석 자료로 사용되었다.

\section{자료분석}

본 연구의 자료분석은 SPSS 20.0 (IBM Co., Armonk, NY)과 PROCESS macro version 3.5 (Model 1; Hayes, 2017)를 사용하여 분석하였다. 첫째, 연구 대상의 인구통계학적 특성을 살펴보기 위하여 빈도분석, 기술통계를 실시하였다. 둘째, 측정도구의 신뢰도를 확인하기 위하여 문항 간 내적합치도 Cronbach's $\alpha$ 계수를 산출하였다. 셋째, 측정 변인 간의 관계를 알아보기 위 해 Pearson 상관관계 분석을 실시하였다. 넷째, 조절효과 검증 을 위해 PROCESS macro (Model 1)를 실시하였으며, 조절효과 에 대한 추가검증을 위해 Johnson-Neyman 기법으로 조절변수 의 유의성 영역을 확인하였다.

\section{Results}

\section{측정 변인들의 일반적 경향}

본 연구에서 측정한 영아의 정서지능과 부정적 정서성, 교사 의 정서사회화 행동(교사의 긍정적 정서표현, 부정적 정서표 현, 정서문제중심 반응, 감정표현중심 반응, 감정표현격려 반 응, 최소화 반응, 처벌적 반응, 스트레스 반응)의 평균 및 표준 
Table 1

Correlation Coefficients Among the Study Variables

\begin{tabular}{|c|c|c|c|c|c|c|c|c|c|c|c|}
\hline & Variables & 1 & 2 & 3 & 4 & 5 & 6 & 7 & 8 & 9 & 10 \\
\hline \multirow{8}{*}{$\begin{array}{l}\text { Teacher's } \\
\text { emotion-related } \\
\text { socialization } \\
\text { behaviors }\end{array}$} & 1. Emotion \& problem-focused reactions & - & & & & & & & & & \\
\hline & 2. Expressive-focused reactions & $.25^{* *}$ & - & & & & & & & & \\
\hline & 4. Minimization reactions & -.06 & $-.26^{* *}$ & $-.16^{*}$ & - & & & & & & \\
\hline & 5. Punitive reactions & $-.30^{* *}$ & $-.18^{*}$ & $-.35^{* *}$ & $.46^{* *}$ & - & & & & & \\
\hline & 7. Positive emotion expression & $.36^{* *}$ & .07 & $.22^{* *}$ & .08 & -.10 & .02 & - & & & \\
\hline & 8. Negative emotion expression & $-.35^{* *}$ & -.07 & $-.19^{* *}$ & .12 & $.36^{* *}$ & $.33^{* *}$ & $-.27^{* *}$ & - & & \\
\hline & 9. Negative emotionality & $-.18^{* *}$ & -.09 & $-.25^{*}$ & $.15^{*}$ & $.33^{* *}$ & .09 & -.01 & $.15^{*}$ & - & \\
\hline & 10. Emotional intelligence & $.29^{* *}$ & $.17^{*}$ & $.43^{* *}$ & $-.15^{*}$ & $-.25^{* *}$ & -.03 & .13 & -.08 & $-.40^{* *}$ & - \\
\hline$M$ & & 5.69 & 5.03 & 5.80 & 3.79 & 1.84 & 3.23 & 4.15 & 1.62 & 2.52 & 3.47 \\
\hline
\end{tabular}

Note. $N=198$.

${ }^{*} p<.05 .{ }^{* *} p<.01$.

편차에 대한 기술통계치와 Pearson 적률상관계수를 산출하여 Table 1에 제시하였다. 영아 정서지능의 평균은 3.47, 부정적 정서성의 평균은 2.52로 나타났다. 교사의 정서사회화 행동 중 영아의 부정적 정서에 대한 교사 반응의 평균은 정서중심 반응 5.69, 문제중심 반응 5.03, 감정표현격려 반응 5.80, 최소 화 반응 3.79, 처벌적 반응 1.84 , 스트레스 반응 3.23 으로 나타 났다. 다음으로 교사의 정서표현성의 평균은 긍정적 정서표현 성이 4.15 , 부정적 정서표현성 1.62 로 나타났다.

한편, 각 변인의 왜도(skewness)와 첨도(kurtosis)는 절대값 \pm 1 의 범위 내로 정규성 가정을 충족하였다(Kline, 2005). 다음으 로 분산팽창요인(VIF) 값이 2 미만으로 나타나 다중공선성상 에 문제가 없는 것으로 판단되었다. 또한, 잔차항들의 상관관 계를 알아보고자 산출한 Durbin-Watson 검정 지수는 1.012 1.804 로 잔차들 간에 상관관계가 없어 모형이 적합한 것을 확 인하였다.

영아의 정서지능은 부정적 정서성 $(r=-.40, p<.01)$ 과 부적 상관이 있는 것으로 나타났으며, 교사의 정서문제중심 반응 $(r=.29, p<.01)$, 감정표현중심 반응 $(r=.17, p<.05)$, 감정표현 격려 반응 $(r=.43, p<.01)$ 과 유의미한 정적상관이 나타난 반 면, 최소화 반응 $(r=-.15, p<.05)$, 처벌적 반응 $(r=-.25, p<.01)$ 과는 유의미한 부적상관이 나타났다. 즉, 교사의 정서사회화 행동, 영아의 부정적 정서성과 정서지능 간의 관련성은 교사 의 스트레스 반응과 영아의 정서지능, 교사의 긍정적 정서표 현성과 영아의 정서지능, 교사의 부정적 정서표현성과 영아의 정서지능 간의 관련성을 제외하고 유의한 것으로 나타났다.

\section{교사의 정서사회화 행동과 영아의 정서지능 간의 관계에서 부정적 정서성의 조절효과}

교사의 정서사회화 행동과 만 2 세 영아의 정서지능 간의 관 계에서 영아의 부정적 정서성의 조절효과를 검증하기 위해 PROCESS macro (Model 1)를 실시하였다. 부트스트래핑은 5,000 회로 지정하였으며, 신뢰구간은 $95 \%$ 로 설정하였다. 변 인 간의 다중공선성을 예방하고자 변인들을 평균중심화하였 다(Cohen, Cohen, West, \& Aiken, 2003). 교사의 정서사회화 행 동의 하위요인 중 조절효과가 유의하게 나온 최소화 반응과 처벌적 반응에 대한 분석결과를 요약하여 제시하였다.

교사의 최소화 반응과 영아의 정서지능 간의 관 계에서 영아의 부정적 정서성의 조절효과

교사의 최소화 반응과 영아의 정서지능 간의 관계에서 영아의 부정적 정서성의 조절효과에 대한 결과는 Table 2에 제시된 바 와 같다.

영아의 정서지능에 대해 교사의 최소화 반응과 영아의 부 정적 정서성의 상호작용 항을 투입한 모형 $(F=9.27, p<.01)$ 에 서 교사의 최소화 반응의 효과는 유의하지 않았으나 $(B=-.06$, $n s)$ 영아의 부정적 정서성 $(B=-.39, p<.001)$ 과 상호작용항 $(B$ $=.19, p<.01)$, 상호작용항에 따른 $R^{2}$ 의 증가량이 유의하여 $\left(R^{2}\right.$ $=.03, p<.05)$ 조절효과가 나타났다. 즉, 교사의 최소화 반응이 영아의 정서지능에 미치는 영향은 영아의 부정적 정서성 수준 
Table 2

Results of the Moderating Effects of Infants' Negative Emotionality in the Relationship Between Teacher's Minimization Reactions and Infants' Emotional Intelligence

\begin{tabular}{|c|c|c|c|c|c|}
\hline \multirow[b]{2}{*}{ Variables } & \multirow[b]{2}{*}{$B$} & \multirow[b]{2}{*}{$S E$} & \multirow[b]{2}{*}{$t$} & \multicolumn{2}{|c|}{$95 \% \mathrm{CI}$} \\
\hline & & & & LLCI & ULCI \\
\hline Minimization reactions (A) & -.06 & .06 & -.92 & -.18 & .06 \\
\hline Negative emotionality (B) & -.39 & .06 & $-6.07^{* * *}$ & -.51 & -.26 \\
\hline$A \times B$ & .19 & .06 & $3.04^{* *}$ & .04 & .32 \\
\hline$R^{2}$ & & & .21 & & \\
\hline$\triangle R^{2}$ & & & .03 & & \\
\hline$F(d f 1, d f 2)$ & & & $9.27^{* *}(1,194)$ & & \\
\hline
\end{tabular}

Note. $N=198$.

${ }^{* *} p<.01 .{ }^{* * *} p<.001$.

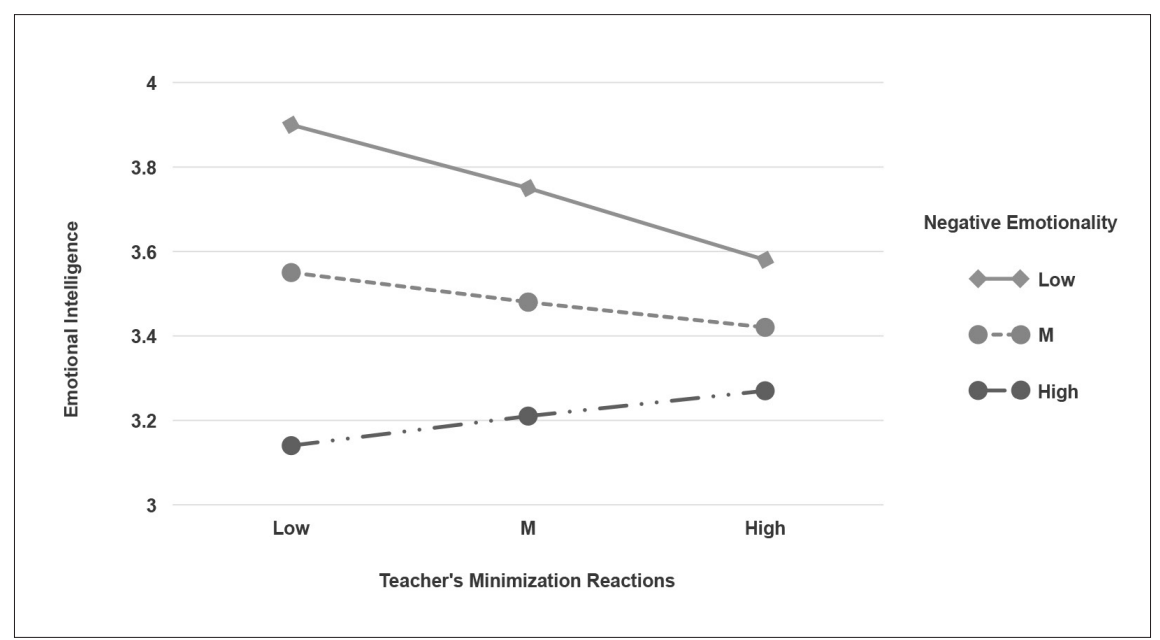

Figure 1. Moderating effects of infant's negative emotionality on the relationship between teacher's minimization reactions and infants' emotional intelligence.

에 따라 달라짐을 의미한다.

영아의 부정적 정서성의 평균값을 중심으로 평균보다 $1 S D$ 높은 집단과 평균 집단, $1 S D$ 낮은 집단으로 나누어 살펴보았 다. 그 결과, 영아의 부정적 정서성 수준이 높을수록 전반적인 정서지능 수준이 낮았다. 또한, 영아의 부정적 정서성이 높은 집단의 경우 교사의 최소화 반응이 영아의 정서지능에 미치 는 영향이 유의하지 않았으며 $(\beta=.06, t=1.36, n s)$, 평균 집단 의 경우에도 유의하지 않은 것으로 나타났다 $(\beta=-.02, t=-.91$, $n s)$. 영아의 부정적 정서성 수준이 낮은 집단의 경우 교사의 최 소화 반응이 영아의 정서지능에 미치는 영향이 유의하였다 $(\beta$ $=-.12, t=-3.10, p<.05)$. 이를 구체적으로 알아보고자 JohnsenNeyman 방법으로 조건부 효과의 유의성 영역을 확인한 결과, 부정적 정서성의 평균 점수 $(M=2.52)$ 이하의 영아에게서 교 사의 최소화 반응이 영아의 정서지능에 미치는 영향이 유의하
였으며, 이는 전체 영아의 $37 \%$ 에 해당하였다. 이를 시각적으 로 살펴보기 위한 조절효과 그래프는 Figure 1에 제시하였다.

교사의 처벌적 반응과 영아의 정서지능 간의 관 계에서 영아의 부정적 정서성의 조절효과

교사의 처벌적 반응과 영아의 정서지능 간의 관계에서 영아의 부정적 정서성의 조절효과에 대한 결과는 Table 3에 제시된 바 와 같다.

분석한 결과, 영아의 정서지능에 대해 교사의 처벌적 반 응과 영아의 부정적 정서성의 상호작용항을 투입한 모형 $(F=$ $9.79, p<.01)$ 에서 처벌적 반응 $(B=-.13, p<.05)$, 부정적 정서 성 $(B=-.34, p<.001)$ 과 상호작용항의 효과 $(B=.19, p<.01)$ 와 상호작용항에 따른 $R^{2}$ 의 증가량이 모두 유의하여 $\left(R^{2}=.03, p\right.$ 
Table 3

Results of the Moderating Effects of Infant's Negative Emotionality on the Relationship Between Teachesr' Punitive Reactions and Infants' Emotional Intelligence

\begin{tabular}{|c|c|c|c|c|c|}
\hline \multirow[b]{2}{*}{ Variables } & \multirow[b]{2}{*}{$B$} & \multirow[b]{2}{*}{$S E$} & \multirow[b]{2}{*}{$t$} & \multicolumn{2}{|c|}{$95 \% \mathrm{CI}$} \\
\hline & & & & LLCI & ULCI \\
\hline Punitive reactions (A) & -.13 & .05 & $-2.63^{* *}$ & -.23 & -.03 \\
\hline$A \times B$ & .19 & .06 & $3.13^{* *}$ & .07 & .31 \\
\hline$R^{2}$ & & & .21 & & \\
\hline
\end{tabular}

Note. $N=198$.

${ }^{* *} p<.01 .{ }^{* * *} p<.001$

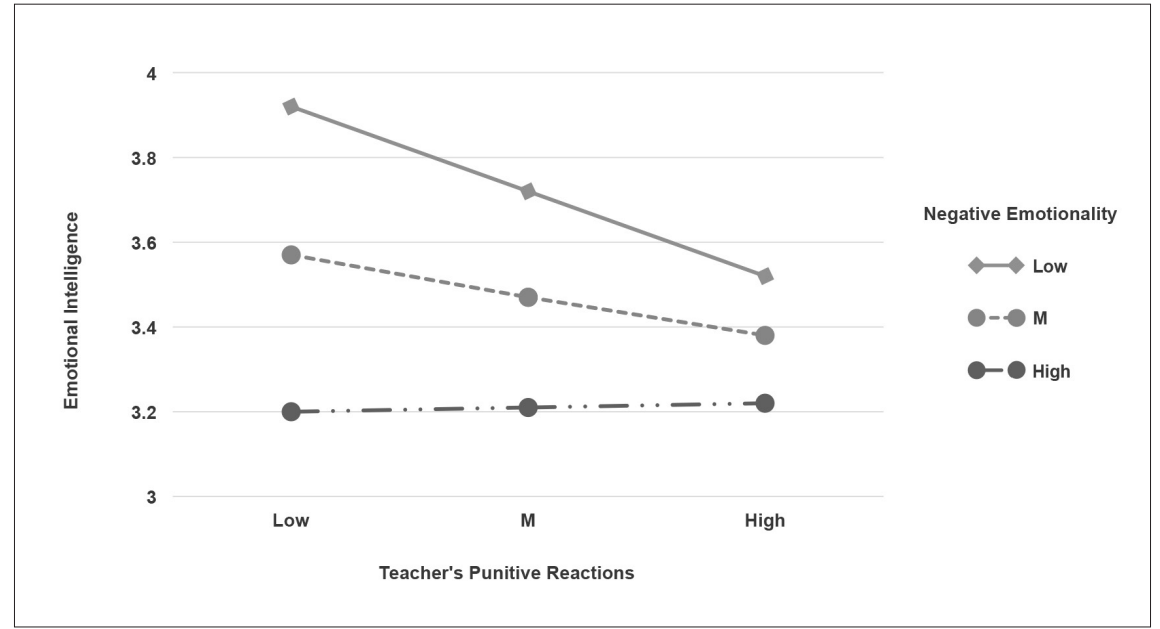

Figure 2. Moderating effects of infants' negative emotionality in the relationship between teachers' punitive reactions and infants emotional intelligence.

<.01) 조절효과가 나타났다. 이는 교사의 처벌적 반응이 영아 의 정서지능에 미치는 영향이 영아의 부정적 정서성 수준에 따라 다름을 의미하는 것이다. 이를 구체적으로 알아보고자 Johnsen-Neyman 방법으로 조건부효과의 유의성 영역을 확인 하였으며 이를 시각적으로 살펴보기 위한 조절효과 그래프는 Figure 2에 제시하였다.

영아의 부정적 정서성의 평균값을 중심으로 평균보다 $1 S D$ 높은 집단과 평균 집단, $1 S D$ 낮은 집단으로 나누어 살펴보았 다. 영아의 부정적 정서성이 높은 집단의 경우 교사의 처벌적 반응이 영아의 정서지능에 미치는 영향이 유의하지 않았으며 $(\beta=.00, t=-.00, n s)$, 평균 집단의 경우 유의한 것으로 나타났 다 $(\beta=-.13, t=-2.63, p<01)$. 또한, 영아의 부정적 정서성 수준 이 낮은 집단의 경우 교사의 처벌적 반응이 영아의 정서지능 에 미치는 영향이 유의하였다 $(\beta=-.26, t=-3.63, p<.001)$. 효
과 크기를 비교해봤을 때, 영아의 부정적 정서성 수준이 낮은 집단에서 교사의 처벌적 반응의 영향이 더 크게 나타났다. 이 를 구체적으로 알아보고자 Johnsen-Neyman 방법으로 조건부 효과의 유의성 영역을 확인한 결과, 부정적 정서성의 평균 점 수 $(M=2.52)$ 이하의 영아에게서 교사의 처벌적 반응이 영아 의 정서지능에 미치는 영향이 유의하였으며, 이는 전체 영아 의 $61 \%$ 에 해당하였다.

\section{Discussion}

본 연구는 만 2세 영아를 대상으로 교사의 정서사회화 행동과 영아의 부정적 정서성이 정서지능에 미치는 영향을 검증하고, 교사의 정서사회화 행동이 영아의 정서지능에 미치는 영향에 
대한 부정적 정서성의 조절효과를 규명하였다. 본 연구의 주 요 결과를 중심으로 논의하고 시사하는 바를 서술하면 다음과 같다.

첫째, 영아의 부정적 정서성은 교사의 정서사회화 행동의 하위요인 중 최소화 반응과 처벌적 반응과 각각 상호작용하여 영아의 정서지능에 유의미한 조절효과를 보였다. 구체적으로 영아의 부정적 정서성이 높은 경우 교사의 최소화 반응과 처 벌적 반응이 영아의 정서지능에 영향을 미치지 않는 반면, 영 아의 부정적 정서성이 낮은 경우 교사가 영아의 부정적 정서 에 대해 최소화하거나 처벌하는 반응을 많이 보일수록 영아의 정서지능 발달을 저해하는 것으로 나타났다. 이는 높은 부정 적 정서성이 환경에 대한 민감한 요인으로 작용하여 부정적인 영향을 더 많이 받을 수 있다는 선행연구의 결과(Broekhuizen, van Aken, Dubas, Mulder, \& Leseman, 2015; I.-Y. Cho, 2016)와 일치하지 않는 것으로 본 연구결과에서 주목해야 할 점이다. 이러한 결과가 나타난 이유로 두 가지 가능성을 제기해보고자 한다.

먼저 영아가 주 양육자와의 애착관계를 통해 형성하는 정 서적·인지적 틀인 '내적 실행모델(interal working model)'에 근 거하여 설명할 수 있다. 영아는 자신의 욕구에 민감하게 반응 해주는 양육자를 통해 안정애착을 형성하게 되면 긍정적인 내 적 실행모델을 형성한다(O.-B. Jung, Chung, \& Hwang, 2009). 특히, 부정적 정서성이 낮을수록 어머니와 긍정적인 상호작용 이 많아(Usai, Garello, \& Viterbori, 2009) 안정애착을 형성할 가 능성이 높다. 안정애착을 형성한 영아는 대체로 타인에 대해 긍정적이며 합리적인 예측을 한다(J. S. Lee \& Cho, 1999). 이 처럼 초기 양육자와의 관계 경험에서 형성한 내적 실행모델은 이후 관계에도 영향을 미치게 된다(McWey, 2004). 하지만, 보 육기관에서는 가정환경과 달리 일대일 상황이 아니기에 교사 가 개별적인 관계에 집중하기 어려울 수 있으며(Yoo, 2020), 부 정적 정서에 대해 무조건적으로 반응해주기보다 집단내의 조 화와 사회적 규칙에 따를 수 있도록 정서표현을 통제하게 된 다. 특히, 영아기는 유아기에 비해 경험이 제한적이므로, 표상 에 기초를 두고 현재의 사건을 해석하고 정서적 기능을 합리 적으로 조절하는데 어려움을 느낄 수 있다. 결과적으로 교사 의 반응에 대해 더 부정적으로 체감하게 됨에 따라 정서지능 발달이 저해되었을 가능성이 있음을 추정해 볼 수 있다. 하지 만 선행연구와는 상반된 결과에 대한 추론이므로 추후 이에 대한 경험적인 연구가 필요할 것으로 사료된다.

다음으로 정서사회화 행동의 비일관성 이론에 따르면, 정 서사회화 행동을 제공하는 대상 간의 비일관성이 주요하게 작
용할 수 있다고 주장한다(Mirabile, 2014). 즉, 부모와 교사가 제공하는 정서사회화 행동 간의 불일치로 인해 영아들이 혼란 스러움을 느끼게 됨에 따라 정서지능 발달에 부정적인 영향 을 미쳤을 가능성이 있다. 이에 부모의 정서사회화 행동과 정 서지능 간의 관계를 검증하였던 선행연구의 결과들(E. Cho \& Shin, 2015; K. M. Jung et al., 2017)과 다른 결과가 도출되었을 수 있다. 하지만, 본 연구에서는 영아의 정서를 사회화시키는 대상으로 교사에만 주목하고 있어 이러한 논의에 대한 제한이 있다. 따라서 추후 연구에서는 정서사회화 행동의 대상이 부 모, 교사, 또래, 형제자매 등으로 다양할 수 있으나 영아와 밀 접한 관계를 맺고 있는 대상의 정서사회화 행동을 함께 고려 하여 진행해 볼 필요가 있다.

한편 부정적 정서성이 높은 영아의 경우 교사가 최소화 반 응이나 처벌적 반응을 보이더라도 정서지능에 미치는 영향력 이 유의하지 않는 것으로 나타났다. 이는 영아의 부정적 정서 성이 높은 경우 환경적인 요인보다 개인 내적 요인인 기질이 정서지능에 더 큰 영향력을 발휘한다는 것을 의미한다. 이는 영아의 사회.정서행동에 아버지의 양육보다 영아의 기질이 더 중요하게 작용한다고 밝힌 선행연구(A. S. Shin, Kim, \& Yoo, 2015)와 비슷한 맥락에서 이해될 수 있다. 이러한 결과는 부정 적 정서성 수준이 높은 영아가 자신의 정서에 압도되어 외부 환경에 대해 크게 영향을 받지 않았을 수 있음을 의미한다. 이 처럼 영아는 기질의 영향을 많이 받는 시기이지만, 발달함에 따라 다양한 환경적 변인에 의해 기질의 영향력이 낮아질 수 있으므로(Brownell \& Hazen, 1999), 교사의 정서사회화 행동이 이후 영아의 발달에 영향을 미칠 수 있음을 고려하지 않을 수 없다.

둘째, 영아의 부정적 정서와 정서지능의 관계에서 교사의 정서중심 반응, 감정표현중심 반응, 감정표현격려 반응에 해 당하는 교사의 지지적인 반응과 교사의 긍정적인 정서표현성 은 조절효과가 없는 것으로 나타났다. 이는 본 연구에서 주요 하게 다루고자한 차별적 민감성 모델의 이론적 가정을 지지 하는 결과가 나타나지 않았음을 의미한다. 이러한 결과는 유 아의 부정적 정서성과 정서조절 간의 관계에서 어머니의 지 지적인 반응에 따른 차이가 나타나지 않은 선행연구 결과(I.Y. Cho, 2016)와도 유사한 맥락으로 볼 수 있다. 이러한 결과가 나타난 점에 대해 다음의 두 가지 방향으로 추론할 수 있다.

먼저 정서지능은 정서를 구분하는 단순한 능력에서부터 타 인에게 감정을 이입하고 대인관계기술을 습득하고, 자신의 성 취나 목적을 위해 정서를 조절하는 등의 일련의 능력들이 통 합된 것으로(Mayer, Salovey, \& Caruso 2000), 연령이 증가함에 
따라 점진적으로 발달한다. 선행연구에서도 정서지능은 유아 기동안에도 연령차가 뚜렷하다는 점이 보고된 바 있다 $(\mathrm{K} . \mathrm{H}$. $\mathrm{Kim} \& \mathrm{Kim}, 2000)$. 즉, 영아기는 정서지능의 기초를 형성해나 가는 단계로 성장하면서 기술을 정교화시키고 발달시켜나간 다는 점에서 교사가 긍정적인 정서를 표현하고 지지적인 반응 을 제공하였을 때 정서지능을 발달시킬 수는 있으나 연령에 따라 점진적으로 발달해간다는 점을 간과할 수는 없다. 즉, 지 지적인 반응을 통해 정서지능 발달에 유의미한 변화가 일어나 기까지 다소 시간이 소요될 수 있기에 횡단연구에서는 그 결 과가 나타나지 않은 것일 수 있으므로, 추후 종단연구를 실시 해 볼 필요가 있다.

다음으로 본 연구결과에서 교사의 정서사회화 행동의 하 위요인 중 문제중심 반응, 감정표현중심 반응, 감정표현격려 반응, 긍정적 정서표현성의 평균 점수가 다소 높은 것으로 나 타났다. 부정적인 정서를 인정하고 지지하는 것은 문제행동 을 극복하는 것에 도움을 줄 수는 있으나 지지적인 반응만 지 속될 시 오히려 유아가 양육자에 대한 의존도가 높아짐에 따 라 지지받지 못하는 상황에서 어려움을 더 크게 느끼며 자신 을 통제하지 못하게 될 수 있다(S. Kim \& Kim, 2018). 또한, 지 지적인 반응에 반복적으로 노출되는 것은 지지적인 피드백에 대해 둔감해지게 만들어 이러한 단서에 더 취약해질 수 있다 (Slagt, Dubas, van Aken, Ellis, \& Deković, 2017). 즉, 교사는 영 아의 부정적 정서가 각성되는 상황에서 긍정적인 정서를 표현 해주거나 지지적으로 반응해주는 것이 도움이 될 수 있지만, 지나치게 지지적인 반응만을 보일 시 부정적 정서가 각성되 는 상황에서 의존적으로 행동하게 될 수 있다. 또한, 이러한 반 응들에 둔감해지게 되면서 긍정적인 피드백에 무관심해 질 수 있으며 결과적으로 정서에 대한 학습을 저해하여 정서지능 발 달에도 부정적인 영향을 미칠 수 있음을 추측해볼 수 있다. 따 라서 영아의 정서지능을 향상시키기 위해서는 지지적이며 긍 정적인 정서사회화 행동과 함께 적정 수준의 제한설정도 제시 할 필요가 있다.

결론적으로 교사의 정서사회화 행동이 영아의 정서지능에 영향을 미치는 정도가 영아의 부정적 정서성 수준에 따라 다 르게 나타남을 알 수 있다. 즉, 부정적 정서성 수준이 낮은 영 아에게 교사가 최소화 반응과 처벌적 반응을 보일수록 이를 더 부정적으로 인식하게 되면서 정서지능 발달이 저해될 수 있음을 의미한다. 이러한 본 연구의 결과를 통해 부정적 정서 성이 낮은 영아들이 환경에 보다 예민하게 반응할 수 있으므 로 일관성있는 정서사회화 행동이 제공되어야 할 필요성이 있 다. 이처럼 영아의 정서지능 발달에 있어 외부환경이 중요하
게 작용할 수 있으나 부정적 정서성과 같은 기질적 요인에 따 라 다른 결과가 도출될 수 있으므로 이를 고려해야 할 필요가 있음을 시사한다. 즉, 부정적 정서성 수준이 낮은 영아에게 교 사가 영아의 정서를 최소화하거나 처벌적으로 반응할수록 영 아는 이를 더 부정적으로 인식하게되면서 정서지능 발달이 저 해될 수 있다. 따라서 만 2세 영아의 정서지능 발달을 저해할 수 있는 요인들을 감소시켜 보육환경에서 적응할 수 있도록 교사의 노력이 동반되어야 함을 시사한다.

본 연구의 제한점와 후속연구를 위한 제언을 하면 다음과 같다. 첫째, 정서지능에 관한 선행연구들은 대부분 유아기에 초점을 맞추고 있으며, 이때 성차 및 연령에 대한 차이가 나타 난다는 결과들이 보고됨에 따라 영아의 정서지능에서도 성차 및 연령에 대한 차이가 나타날 것으로 기대되나 이에 대한 기 초 분석이 부족한 실정이므로 이를 고려한 모형을 검토하지 못하였다. 따라서 후속연구에서는 영아의 정서지능에서 성차 및 월령 등을 고려해야 할 필요성이 있다.

둘째, 교사의 자기보고로 연구변인을 측정하였다. 이때, 교 사의 주관적 판단으로 인해 사회적으로 바람직한 방향으로 답 하고자 하는 오류가 포함되었을 가능성이 있다. 따라서 후속 연구에서는 수집원 및 측정방법을 다양화하여 자료의 독립성 확보와 자기보고 편향의 가능성을 줄이고자 하는 노력이 필요 할 것으로 사료된다. 셋째, 부모와 교사는 모두 영아의 정서를 사회화시키는 대상으로 영아의 정서지능을 촉진하거나 억제 하는 경험을 제공한다는 점에서 부모의 영향력을 통제하지 않 았다는 한계점이 있다. 선행연구에 의하면 정서사회화를 제공 하는 대상 간의 비일관성이 혼란을 주기도 한다는 점을 비춰 봤을 때, 영아의 밀접한 접촉 대상이 모두 영향을 미칠 수 있으 므로 이후 연구에서는 부모의 영향력을 통제하거나 부모와 교 사의 정서사회화 행동을 함께 고려하여 살펴볼 필요가 있다. 넷째, 본 연구에서 사용한 부정적 정서에 대한 교사 반응 척도 는 국외에서 개발되어 타당화가 이루어진 척도이나 국내에서 적용되는 것은 초기 단계이다. 향후 국내 실정에 맞게 적용하 기 위해 타당화를 거친 척도를 사용할 필요가 있다.

이러한 제한점에도 불구하고 본 연구는 만 2 세 영아의 정서 지능에 영향을 미치는 요인을 경험적으로 확인하였다는 점에 서 의의가 있다. 다음으로, 교사는 이차적 양육자로서 그 중요 성이 대두되고 있음에도 부모에 초점이 맞춰져 교사의 정서사 회화에 관한 연구들은 다소 부족하였다. 하지만 본 연구에서 는 교사의 정서사회화 행동의 역할을 규명하고자 시도하였으 며, 영아의 정서지능 발달에 있어 교사의 정서사회화 행동의 역할을 확인하였다. 마지막으로 교사의 정서사회화 행동과 영 
아의 정서지능의 관계에서 영아의 부정적 정서성이 조절한다 는 것을 밝힘으로써 영아의 낮은 부정적 정서성 수준이 교사 의 정서사회화 행동과 상호작용하여 정서지능 발달에 부정적 인 영향을 미칠 수 있는 요인임을 확인하였다. 본 연구는 정서 지능의 기초가 형성되는 만 2 세 영아기에 정서지능의 발달을 도모할 수 있는 프로그램 개발 및 개입 방안을 위한 기초자료 로 활용될 수 있을 것이다.

\section{Notes}

This article is a part of the first author's master's thesis submitted in 2020, and was presented as a poster at the 2019 Annual Fall Conference of the Korean Association of Child Studies.

\section{Conflict of Interest}

No potential conflict of interest relevant to this article was reported.

\section{References}

\section{In English}

Albrecht, T. L., Burleson, B. R., \& Goldsmith, D. (1994). Supportive communication. In M. L. Knapp \& G. R. Miller (Eds.), Handbook of interpersonal communication (2nd ed., pp. 419-449). Thousand Oaks, CA: Sage.

Alegre, A. (2011). Parenting styles and children's emotional intelligence: What do we know? The Family Journal, 19(1), 56-62. doi:10.1177/1066480710387486

Bar-On, R. (2000). Practical guide of applying emotional intelligence to improve personal and organizational effectiveness. New York: Academic Press.

Bassett, H. H., Denham, S. A., Fettig, N. B., Curby, T. W., Mohtasham, M., \& Austin, N. (2017). Temperament in the classroom: Children low in surgency are more sensitive to teachers' reactions to emotions. International Journal of Behavioral Development, 41(1), 4-14. doi:10.1177/0165025416644077

Belsky, J. (2013). Differential susceptibility to environmental influences. International Journal of Child Care and Education Policy, 7(2), 15-31. doi:10.1007/2288-6729-7-2-15

Belsky, J., \& Pluess, M. (2009). Beyond diathesis stress: Differential susceptibility to environmental influences. Psychological Bulletin, 135(6), 885-908. doi:10.1037/a0017376

Broekhuizen, M. L., van Aken, M. A. G., Dubas, J. S., Mulder, H., \& Leseman, P. P. M. (2015). Individual differences in effects of child care quality: The role of child affective selfregulation and gender. Infant Behavior and Development, 40, 216-230. doi:10.1016/j.infbeh.2015.06.009

Brownell, C. A., \& Hazen, N. (1999). Early peer interaction: A research agenda. Early Education and Development, 10(3), 403-413. doi:10.1207/s15566935eed1003_9

Cohen, J., Cohen, P., West, S. G., \& Aiken, L. S. (2003). Applied multiple regression/correlation analysis for the behavioral sciences (3rd ed.). Mahwah, NJ: Lawrence Erlbaum.

Denham, S. A. (1998). Emotional development in young children. New York: Guilford Press.

Denham, S. A., \& Bassett, H. H. (2019). Early childhood teachers' socialization of children's emotional competence. Journal of Research in Innovative Teaching \& Learning, 12(2), 133150. doi:10.1108/JRIT-01-2019-0007

Denham, S. A., Bassett, H. H., \& Miller, S. L. (2017). Early childhood teachers' socialization of emotion: Contextual and individual contributors. Child \& Youth Care Forum, 46(6), 805-824. doi:10.1007/s10566-017-9409-y

Denham, S. A., Bassett, H. H., Thayer, S. K., Mincic, M. S., Sirotkin, Y. S., \& Zinsser, K. (2012). Observing preschoolers' social-emotional behavior: Structure, foundations, and prediction of early school success. The Journal of genetic psychology, 173(3), 246-278. doi:10.1080/00221325.2011.5 97457

Denham, S. A., Bassett, H. H., \& Zinsser, K. (2012). Early childhood teachers as socializers of young children's emotional competence. Early Childhood Education Journal, 40, 137-143. doi:10.1007/s10643-012-0504-2

Denham, S. A., Ferrier, D. E., \& Bassett, H. H. (2020). Preschool teachers' socialization of emotion knowledge: Considering socioeconomic risk. Journal of Applied Developmental Psychology, 69, 101160. doi:10.1016/j.appdev.2020.101160

Eisenberg, N., Cumberland, A., \& Spinrad, T. L. (1998). Parental socialization of emotion. Psychological Inquiry, 9(4), 241273. doi:10.1207/s15327965pli0904_1

Goleman, D. (1995). Emotional intelligence. New York: Bantam books.

Goleman, D. (2001). Emotional intelligence: Issues in paradigm building. In C. Cherniss \& D. Goleman (Eds.), The emotionally intelligence workplace (pp. 13-26). San Francisco, CA: Jossey-Bass.

Hayes, A. F. (2017). Introduction to mediation, moderation, and conditional process analysis: A regression-based approach (2nd ed.). New York: Guilford Press.

Izard, C. E. (1991). The psychology of emotions. New York: Plenum. 
Kline, T. J. (2005). Psychological testing: A practical approach to design and evaluation. Thousand Oaks, CA: Sage.

Kostelnik, M., Soderman, A., Whiren, A., Rupiper, M. L., \& Gregory, K. (2015). Guiding children's social development and learning: Theory and skills. Stamford, CT: Cengage Learning.

Mayer, J. D., Salovey, P., Caruso, D. (2000). Models of emotional intelligence. In R. J. Sternberg (Ed.), Handbook of Intelligence. New York: Cambridge University Press.

McWey, L. M. (2004). Predictors of attachment styles of children in foster care: An attachment theory model for working with families. Journal of Marital and Family Therapy, 30(4), 439-452. doi:10.1111/j.1752-0606.2004.tb01254.x

Mirabile, S. P. (2014). Parents' inconsistent emotion socialization and children's socioemotional adjustment. Journal of Applied Developmental Psychology, 35(5), 392-400. doi:10.1016/ j.appdev.2014.06.003

Paterson, A. D., Babb, K. A., Camodeca, A., Goodwin, J., HakimLarson, J., Voelker, S., \& Gragg, M. (2012). Emotionrelated parenting styles (ERPS): A short form for measuring parental meta-emotion philosophy. Early Education and Development, 23(4), 583-602. doi:10.1080/10409289.201 1.569316

Rim-Kaufman, S., Pianta, R. C., \& Cox, M. J. (2000). Teachers' judgments of problems in the transition to kindergarten. Early Childhood Research Quarterly, 15(2), 147-166. doi:10.1016/S0885-2006(00)00049-1

Rothbart, M. K., \& Bates, J. E. (2006). Temperament. In W. Damon \& R. M. Lerner (Series Eds.) \& N. Eisenberg (Vol. Ed.), Handbook of child psychology (6th ed., Vol. 3, pp. 99166). Hoboken, NJ: John Wiley \& Sons.

Salovey, P., \& Mayer, J. D. (1990). Emotional intelligence. Imagination, Cognition, and Personality, 9(3), 185-211. doi:10.2190/DUGG-P24E-52WK-6CDG

Slagt, M., Dubas, J. S., van Aken, M. A., Ellis, B. J., \& Deković, M. (2017). Children's differential susceptibility to parenting: An experimental test of for better and for worse. Journal of Experimental Child Psychology, 154, 78-97. doi:10.1016/ j.jecp.2016.10.004

Usai, M. C., Garello, V., \& Viterbori, P. (2009). Temperamental profiles and linguistic development: Differences in the quality of linguistic production in relation to temperament in children of 28 months. Infant Behavior and Development, 32, 322-330. doi:10.1016/j.infbeh.2009.04.001

Valiente, C., Swanson, J., DeLay, D., Fraser, A. M., \& Parker, J. H. (2020). Emotion-related socialization in the classroom: Considering the roles of teachers, peers, and the classroom context. Developmental Psychology, 56(3), 578-594. doi:10.1037/dev0000863

\section{In Korean}

Cho, B. W. (2012). Study on dependence of preschoolers' emotional intelligence on mothers' parenting efficacy and verbal control style. Journal of Future Early Childhood Education, 19(2), 133-157.

Cho, E., \& Shin, N. (2015). The effects of maternal meta-emotion and emotion socialization on preschoolers' emotional intelligence. Korean Journal of Child Studies, 36(2), 145-166. doi:10.5723/KJCS.2015.36.2.145

Cho, I.-Y. (2016). The relationship between children's negative emotions and emotional regulation ability on peer competence: Mediating and moderating effects of mother's reactions to children's negative emotions (Doctoral disseration). Retreived from http://www.riss.kr/link?id=T14138586

Choi, E. S. (2002). A study on the relations among the emotionality, emotion regulation and the peer popularity of children. Korean Journal of Child Education and Care, 2(1), 173-187.

Choi, J., \& Shin, N. (2018). Effects of infant's negative emotionality and mother's affective parenting on externalizing problem behaviors in preschool years: A longitudinal study using latent growth modeling. The Korean Journal of the Human Development, 25(3), 51-71. doi:10.15284/kjhd.2018.25.3.51

Choi, M.-S., Kong, J.-H., \& Park, E.-Y. (2012). The relationships between maternal child-rearing attitude and children's emotional intelligence and problem behavior. Journal of Parent Education, 4(2), 33-51.

Jung, K. M., Yoon, N. Y., \& Ahn, S. H. (2017). Mother's reactions to children of high negative emotionality and children's emotional intelligence. Journal of Korean Council for Children \& Rights, 21(4), 565-583. doi:10.21459/kccr.2017.21.4.565

Jung, O.-B., Chung, S.-H., \& Lim, J.-H. (2007). Emotional development \& emotional intelligence. Seoul: Hakjisa.

Jung, O.-B., Chung, S.-H., \& Hwang, H. J. (2009). Attachment \& development. Seoul: Hakjisa.

Kang, J. W., \& Kim, S. L. (2018). The effects of fathers' parenting participation and emotional empathy on two-year olds' emotional intelligence. Korean Journal of Human Ecology, 27(5), 321-333. doi:10.5934/kjhe.2018.27.5.321

Kim, B. Y. (2016). The effect of children's executive function, selfesteem and emotional intelligence on peer competence. Early Childhood Education \& Care, 11(3), 29-51. doi:10.16978/ ecec.2016.11.3.002

Kim, E. K., \& Kim, S. L. (2019). The effects of young children's emotional intelligence and prosocial behaviors on their leadership. The Journal of Convergence on Culture Technology, 5(1), 169-175. doi:10.17703/JCCT.2019.5.1.169

Kim, J. E., \& Shin, Y. L. (2015). The influences of negative emotionality, effortful control, and parent-child relationship on emotion regulation of preschoolers. The Journal of Eco 
Early Childhood Education \& Care, 14(1), 219-237.

Kim, J. Y., Dah, H. S., \& Kim, M. J. (2008). Problem behavior of preschool children: The influence of marital conflict and of children's temperament and emotion regulation. Korean Journal of Child Studies, 29(5), 133-150.

Kim, K. H., \& Kim, K. H. (2000). Developmental trends of children's emotional intelligence. Korean Journal of Child Studies, 21(4), 21-34.

Kim, N. H., Yeon, G. S., \& Oh, Y. T. (2018). An analysis of the relationships among children's emotional intelligence, selfesteem, problem behavior and intellectual capacity. Korean Journal of Early Childhood Education, 38(2), 447-468. doi: 10.18023/kjece.2018.38.2.018

Kim, S., \& Kim, W. (2018). The relationship among mothers' metaemotion, mothers' response to children's negative emotions, children's ego-resilience, and problem behavior. The Journal of Yeolin Education, 26(1), 31-53. doi:10.18230/tjye.2018.26.1.31

Kim, Y. E. (2014). The effect of toddlers' negative emotionality and mothers' reactions to their child's negative emotions of socialemotional behaviors. Journal of Korean Child Care and Education, 10(3), 85-102. doi:10.14698/jkcce.2014.10.3.085

Lee, J. S., \& Cho, B. H. (1999). Preschool children's representation of attachment: Associations with teacher-child relationship and social competence. Korean Journal of Child Studies. 22(3), 17-29.

Lee, J. Y., Lee, H. S., Jang, M., \& Sung, J. (2019). Effects of maternal parenting efficacy on emotional intelligence among 36-month-old children: Mediating roles of maternal emotional expression and children's language development level. Korean Journal of Child Studies, 40(3), 1-12.

Moon, Y. L. (2011). Professor Mun-Yong Lin's lecture on emotional intelligence. Seoul: Booksnut.

Nam, H.-J., \& Seo, H.-A. (2008). Children's emotional intelligence according to mother's emotional expressiveness and verbal control style. The Journal of Humanities, 13(2), 91-116.

Oh, J. (2010). Analysis of teachers' discourses on infants' negative emotional expressions (Master's thesis). Retrieved from http://www.riss.kr/link?id=T12150579

Oh, S. M. (2017). The effect of teacher's emotional expressiveness on young children's emotional intelligence: Focusing on the moderating effect of teacher's emotional intelligence (Master's thesis). Retrieved from http://www.riss.kr/link?id=
T14428523

Park, J.-Y., Kim, Y-S., \& Bae, S.-M. (2016). The mediating effect of personality on the relationship between playfulness and emotional intelligence in young children. Journal of Early Childhood Education \& Educare Welfare, 20(2), 85-106.

Shin, A. S., Kim, K., \& Yoo, J. E. (2015). The influence of infant temperament and father's involvement in child-rearing on infants social and emotional behavior. Korean Journal of Child Education and Care, 15(3), 173-191.

Yoo, J. (2020). A comparison of dual-income family toddlers' attachment to mothers and teachers and effects of toddlers' temperament to attachment. Journal of Early Childhood Education \& Educare Welfare, 24(1), 153-176. doi:10.22590/ ecee.2020.24.1.153

Yoo, J., \& Yi, S.-H. (2016). A comparison of effects of toddler's temperament and teacher-toddler relationship on peer interaction: Focusing on gender differences. Journal of Korean Child Care and Education, 12(4), 93-110. doi:10.14698/ jkcce.2016.12.04.093

Yoon, S.-J., \& Park, H.-S. (2016). The effects of autonomy of toddler and peer interactions on emotional intelligence and toddlerteacher interactions in 24-hour childcare centers. Early Childhood Education of Care, 11(2), 157-173. doi:10.16978/ ecec.2016.11.2.007

Yoon, Y. H., \& Shim, S.-Y. (2017). The relationship between mother's psychological wellbeing and infant's emotional intelligence. The Korea Association of Child and Education, 1(1), 47-66.

\section{ORCID}

So Ra Bae https://orcid.org/0000-0002-3116-5612

Sunhee Kim http://orcid.org/0000-0002-0801-6918

Received October 31, 2020

Revision received March 01, 2021

Accepted March 22, 2021 